\title{
Acute toxicity tests with Daphnia magna, Americamysis bahia, Chironomus riparius and Gammarus pulex and implications of new EU requirements for the aquatic effect assessment of insecticides
}

\author{
Theo C. M. Brock • René P. A. Van Wijngaarden
}

Received: 12 December 2011 / Accepted: 12 April 2012/Published online: 5 May 2012

(C) The Author(s) 2012. This article is published with open access at Springerlink.com

\begin{abstract}
Threshold concentrations for treatment related effects of 31 insecticides, as derived from aquatic micro-/ mesocosm tests, were used to calibrate the predictive value of the European Tier-1 acute effect assessment on basis of laboratory toxicity tests with Daphnia magna, Chironomus spp., Americamysis bahia and Gammarus pulex. The acute Tier-1 effect assessment on basis of Daphnia $\left(\mathrm{EC}_{50} / 100\right)$ overall was protective for organophosphates, carbamates and most pyrethroids but not for neonicotinoids and the majority of insect growth regulators (IGRs) in the database. By including the 28-day water-spiked Chironomus riparius test, the effect assessment improves but selecting the lowest value on basis of the 48-h Daphnia test (EC50/100) and the 28-day Chironomus test (NOEC/10) is not fully protective for 4 out of 23 insecticide cases. An assessment on basis of G. pulex $\left(\mathrm{EC}_{50} / 100\right)$ is sufficiently protective for 15 out of 19 insecticide cases. The Tier-1 procedure on basis of acute toxicity data $\left(\mathrm{EC}_{50} / 100\right)$ for the combination of Daphnia and A. bahia and/or Chironomus (new EU dossier requirements currently under discussion) overall is protective to pulsed insecticide exposures in micro-/mesocosms. For IGRs that affect moulting, the effect assessment on basis of the 48-h Chironomus test $\left(\mathrm{EC}_{50} / 100\right)$ may not always be protective enough to replace that of the water-spiked 28-day C. riparius test $(\mathrm{NOEC} / 10)$ because of latency of effects.
\end{abstract}

Keywords Ecotoxicology · Aquatic invertebrates · Tier I · Micro-/mesocosms $\cdot$ Calibration

\section{Responsible editor Henner Hollert}

T. C. M. Brock $(\bowtie) \cdot$ R. P. A. Van Wijngaarden

Alterra, Wageningen University and Research Centre,

P.O. Box 47, 6700 AA Wageningen, The Netherlands

e-mail: theo.brock@wur.nl

\section{Introduction}

Tiered approaches are the basis of environmental risk assessment schemes that support the registration of pesticides (e.g. Campbell et al. 1999; EC 2002; Boesten et al. 2007; Solomon et al. 2008). In this context, a Tier is defined as a complete exposure or affects assessment resulting in an appropriate predicted environmental concentration (PEC) or regulatory acceptable concentration (RAC). The concept of tiered approaches is to start with a simple conservative assessment and to do additional more complex work if necessary, but all tiers within the same scheme need to address the same specific protection goal (EFSA 2010; Nienstedt et al. 2011). This approach implies a costeffective procedure both for industry and regulatory agencies. In the aquatic effect assessment Tier-1 normally is based on results of laboratory toxicity tests with a limited number of standard test species and the application of an appropriate assessment factor (AF). Subsequent higher tiers may include results of laboratory toxicity test with additional test species (allowing, e.g. the species sensitivity distribution (SSD) approach), aquatic micro-/mesocosm tests (model ecosystem approach), and 'validated' food-web and /or population models (Fig. 1). The tiered system as a whole needs to be: (1) appropriately protective, (2) internally consistent, (3) cost-effective and (4) address the problem with a higher degree of realism and complexity when going from lower to higher tiers. In pesticide risk assessment under Regulation (EC) no. 1107/2009 (EC 2009), the basic data requirement for the Tier-1 effect assessment are strictly defined (EC 2011). The current Tier-1 basic data requirement, however, are under discussion (see below), since the new Regulation 1107/2009 not only aims an appropriate protection of crops against harmful organisms but also a higher level of protection of the environment and non-target 
organisms than under the former Plant Protection Product Directive (91/414/EEC) (EC 1991).

A logical consequence of the principles of the tiered approach in the environmental risk assessment for pesticides is that results of an appropriate higher tier effect assessment may act as a reference to calibrate the lower tier effect assessment, because the assessment endpoint derived from a higher tier is closer to the actual objectives of the adopted protection goal (Fig. 1). In the aquatic effects assessment for pesticides, a micro-/mesocosm test may provide the appropriate higher tier effect endpoint when invertebrates or primary producers are at risk (Brock et al. 2006; Maltby et al. 2005, 2009; Van den Brink et al. 2006; Guy et al. 2011). In this paper, we therefore use threshold concentrations for treatmentrelated effects as observed in micro-/mesocosm studies treated with insecticides to calibrate the Tier-1 acute effect assessment procedure.

The main objective of this paper is to evaluate the Tier1 effect assessment procedure for insecticides based on the current and the proposed new, but not yet adopted, EU dossier data requirement for acute toxicity to aquatic invertebrates. The risk assessment procedure on basis of the current data requirement is described in the EU Guidance Document on Aquatic Ecotoxicology (EC 2002) and in Commission Regulation No 544 (EC 2011). According to these documents, the acute insecticide risk to invertebrates is assessed by comparing the predicted peak concentration $\left(\mathrm{PEC}_{\max }\right)$ for edge-of-field surface water with the Daphnia 48 -h $\mathrm{EC}_{50} / 100$ value. In addition, according to EC (2002), an effect assessment on basis of the 28-day

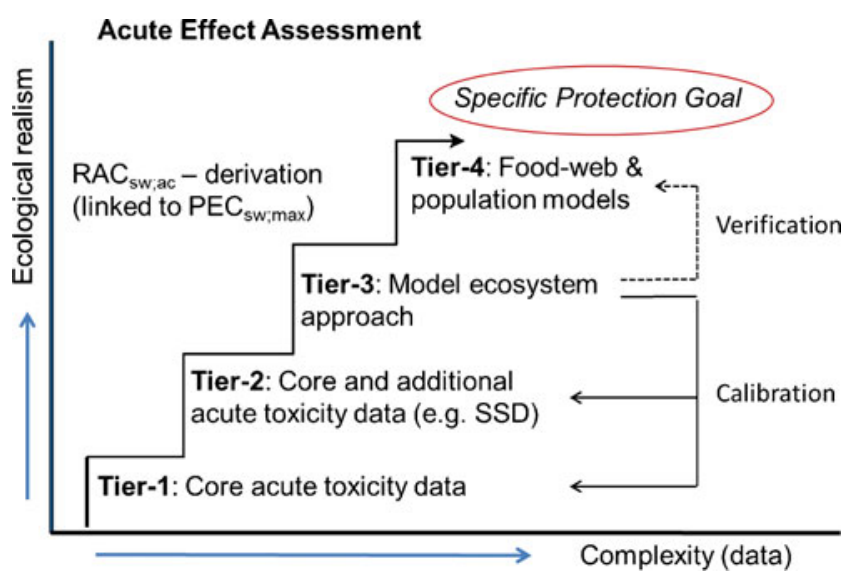

Fig. 1 Schematic presentation of the tiered approach within the acute effect assessment for pesticides showing the refinement of the process through the acquisition of additional data and the possibility to use results of micro-/mesocosms (model ecosystem approach) to calibrate the lower tiers. $R A C_{S w ;}$ ac the Regulatory Acceptable Concentration for surface water within the context of the acute effect assessment scheme, $P E C_{S w \text {; } \max }$ the maximum concentration predicted for surface water, SSD Species Sensitivity Distribution approach (redrafted after Solomon et al 2008 and EFSA 2010) water-spiked Chironomus test in the presence of sediment (OECD 2004; Streloke and Köpp 1995) should be provided if the test substance concerns an insecticide with a specific toxic mode-of-action (e.g. neonicotinoid insecticide and insect growth regulator (IGR); Daphnia 48h EC50>1 mg/L). In this 28-day water-spiked Chironomus test, the exposure concentration of the test compound is not maintained in the water compartment, and the effect endpoint (i.e. NOEC or $\mathrm{EC}_{10}$ ) is expressed in terms of the initial (nominal) exposure concentration in water. In the risk assessment on basis of this test the derived NOEC/ $\mathrm{EC}_{10}$ is divided by an $\mathrm{AF}$ of 10 , and the concentration thus obtained is compared with the $\mathrm{PEC}_{\max }$. The Guidance Document on Aquatic Ecotoxicology (EC 2002) also states that for the acute effect assessment of insecticides like neonicotinoids and IGRs, a water-only acute Chironomus test may be appropriate, but that an official guideline for such a test needs to be developed.

For pesticide risk assessment under the new Plant Protection Product Regulation (EC 2009), commission regulation (EU) proposals circulate to revise the basic data requirement for the first-tier aquatic effect assessment. An important change in the proposed update is the inclusion of an acute test for a second aquatic arthropod species (besides Daphnia) as basic data requirement for insecticides and substances with insecticidal activity. The Mysid shrimp (Americamysis bahia) and/or larvae of the insect Chironomus spp. are mentioned as candidate. Since A. bahia is a saltwater crustacean, the insect Chironomus is considered a more relevant freshwater test species and an official OECD guideline for an acute aquatic tests with Chironomus has recently been published (OECD 2011; also see Weltje et al. 2010). Consequently, when in the near future the proposed new data requirement will be implemented, the acute toxicity to aquatic invertebrates will, in the first instance, be assessed on basis of (1) the acute laboratory $48-\mathrm{h} \mathrm{EC}_{50}$ for Daphnia (preferably Daphnia magna) and (2) the acute 48$\mathrm{h} \mathrm{EC}_{50}$ for $A$. bahia and/or C. riparius (or another Chironomus species mentioned in OECD (2011) such as Chironomus dilutus or Chironomus yoshimitsui). In the first-tier effect assessment an AF of 100 will be applied to the lowest acute $\mathrm{EC}_{50}$ value. The highest predicted peak concentration $\left(\mathrm{PEC}_{\max }\right)$ in edge-of-field surface water should not exceed the Tier-1 regulatory acceptable concentration (Tier-1 RAC) thus obtained. This risk assessment procedure is believed to sufficiently protect non-target invertebrates that dwell in edge-of-field surface waters from short-term exposures to insecticides.

In the current paper, we intend to evaluate the implication of the proposed new aquatic data requirement (inclusion of acute tests with A. bahia and/or Chironomus spp.) for the Tier-1 acute effect assessment for insecticides. In addition, we also explore whether the macro- 
Table 1 Insecticides used for the evaluation and related scientific papers in the open literature that were consulted in addition to the open access toxicity data bases mentioned in the "Materials and methods" section

\begin{tabular}{|c|c|c|}
\hline Group & Compound & Open literature references \\
\hline \multirow[t]{6}{*}{ Organophosphates } & Azinphos-methyl & Van Wijngaarden et al. (2005a) and Maltby et al. (2005) \\
\hline & Chlorpyrifos & $\begin{array}{l}\text { Daam et al. (2008), López-Mancisidor et al. (2008), } \\
\text { Maltby et al. (2005), Van den Brink et al. (1996), and } \\
\text { Van Wijngaarden et al. (2005b) }\end{array}$ \\
\hline & Fenitrothion & Van Wijngaarden et al. (2005a) and Maltby et al. (2005) \\
\hline & Parathion-ethyl & Van Wijngaarden et al. (2005a) and Maltby et al. (2005) \\
\hline & Phosalone & \\
\hline & Phosmet & \\
\hline \multirow[t]{2}{*}{ Carbamates } & Carbaryl & $\begin{array}{l}\text { Ashauer et al. (2011), Maltby et al. (2005), and Van } \\
\text { Wijngaarden et al. (2005a) }\end{array}$ \\
\hline & Carbofuran & Van Wijngaarden et al. (2005a) and Maltby et al. (2005) \\
\hline \multirow[t]{8}{*}{ Pyrethroids } & Cypermethrin & Maltby et al. (2005) \\
\hline & Deltamethrin & $\begin{array}{l}\text { Åkerblom et al. (2008), Beketov (2004), Maltby et al. } \\
\text { (2005), } \\
\text { and De Knecht and Van Herwijnen (2008) }\end{array}$ \\
\hline & Esfenvalerate & $\begin{array}{l}\text { Beketov (2004), Beketov and Liess (2008a), Lozano } \\
\text { et al. (1992), Webber et al. (1992), and Van } \\
\text { Vlaardingen et al. (2008) }\end{array}$ \\
\hline & Fenvalerate & Van Wijngaarden et al. (2005a) and Maltby et al. (2005) \\
\hline & $\begin{array}{l}\text { Gamma- } \\
\text { cyhalothrin }\end{array}$ & Van Wijngaarden et al. (2009) and Giddings et al. (2009) \\
\hline & $\begin{array}{l}\text { Lambda- } \\
\text { cyhalothrin }\end{array}$ & $\begin{array}{l}\text { Van Leeuwen et al. (2008), Maund et al. (2008), Roessink } \\
\text { et al. (2005), Schroer et al. (2004), and Van Wijngaarden } \\
\text { et al. (2006) }\end{array}$ \\
\hline & Bifenthrin & \\
\hline & Acrinathrin & \\
\hline \multirow{5}{*}{$\begin{array}{l}\text { Benzylurea \& other } \\
\text { IGRs }\end{array}$} & Diflubenzuron & Brock et al. (2006) and Maltby et al. (2005) \\
\hline & Novaluron & \\
\hline & Teflubenzuron & Scheepmaker (2008a) \\
\hline & Fenoxycarb & Smit and Vonk (2008) \\
\hline & Pyriproxifen & Moermond (2008) \\
\hline \multirow[t]{2}{*}{ Biopesticides } & Abamectin & Scheepmaker (2008b) \\
\hline & Milbemectin & \\
\hline \multirow[t]{4}{*}{ Neonicotinoids } & Clothianidin & \\
\hline & Imidacloprid & $\begin{array}{l}\text { Ashauer et al. (2011), Beketov and Liess (2008a), } \\
\text { Posthuma-Doodeman (2008), and Stoughton et al. } \\
\text { (2008) }\end{array}$ \\
\hline & Thiacloprid & $\begin{array}{l}\text { Beketov and Liess (2008b), Beketov et al. (2008), } \\
\text { and Langer-Jaesrich et al. (2011) }\end{array}$ \\
\hline & Thiamethoxam & \\
\hline \multirow[t]{4}{*}{ Other insecticides } & Lindane & Brock et al. (2006) and Maltby et al. (2005) \\
\hline & Methoxychlor & Brock et al. (2006) and Maltby et al. (2005) \\
\hline & Flubendiamide & \\
\hline & Spiromesifen & \\
\hline
\end{tabular}

crustacean Gammarus pulex is potentially a suitable standard test species for the risk assessment of insecticides since this species has been widely used in toxicity testing and is often used as focal species for developing ecotoxicological models (e.g. Galic et al. 2010; Ashauer et al. 2007, 2011).

\section{Materials and methods}

Single-species acute toxicity data and micro-/mesocosm data were collected from existing open access toxicity data bases such as ECOTOX (www.epa.gov/ecotox/), Footprint (www.eu-footprint.org/ppdb.html), open "grey" literature 
including EU Draft Assessment Reports or DARs (http:// dar.efsa.europa.eu/dar-web/provision ), RIVM reports (www.rivm.nl/bibliotheek/index-en.html), summary reports of EU member states (e.g. www.ctgb.nl) and scientific papers in the open literature (see Table 1). In addition, confidential data from industry was used that was provided to Alterra and used in the paper of Maltby et al. (2005). Insecticides were allocated to one of the following categories: organophosphates, carbamates, pyrethroids, insect growth regulators, neonicotinoids, biopesticides and other types of insecticides (Table 1).To respect the confidentiality of the data provided by industry, we made the different insecticides anonymous in the graphs but allocated them to one of the insecticide categories listed above. Criteria used to select single-species toxicity data were test endpoint and duration. Outliers where checked using original publications (i.e. sensu Maltby et al. 2005). Selected endpoints were the median effect concentrations for immobility or mortality observed in toxicity tests $\left(\mathrm{EC}_{50}\right)$. The test duration selected was 48-96 h. Geometric means were calculated when more than one toxicity value was reported for the same endpoint of a species.

Micro-/mesocosm data were used to derive safe threshold concentrations. Each study was classified into one of two exposure categories, namely (1) a single pulse exposure regime or (2) a repeated exposure regime. In addition, responses observed for the most sensitive endpoint of a study were ascribed to one of five effect classes (sensu Brock et al. 2006; De Jong et al. 2008). For each compound and exposure regime the $\mathrm{NOEC}_{\text {eco }}$ (=threshold concentration for treatment-related effects) was derived from test concentrations at which no statistical and ecological significant effects (Effect Class 1) or slight/transient effects on individual samplings only (Effect Class 2) were observed for the most sensitive population and/or community endpoint. When possible, for each compound a separate NOE$\mathrm{C}_{\text {eco }}$ data point for a single and a repeated treatment regime was derived. Construction of the $\mathrm{NOEC}_{\mathrm{eco}}$ was as follows. In case only Effect Class 1 values were available, then this value was used as the $\mathrm{NOEC}_{\text {eco. }}$. In case only Effect Class 2 values were available, then this value was divided by two ((Effect Class 2 concentration)/2) to estimate the $\mathrm{NOEC}_{\text {eco. }}$. When both an Effect Class 1 and an Effect Class 2 value were available then the geometric mean of the Class 1 and Class 2 values was used as the $\mathrm{NOEC}_{\text {eco. In case more }}$ Effect Class 1 values were available for a compound (e.g. from different micro-/mesocosm studies), then the highest of these values was used. In the same situation for Effect Class 2 values, the lowest Class 2 value was chosen.

Ecosystem threshold levels $\left(\mathrm{NOEC}_{\mathrm{eco}}\right)$ were then compared with arthropod first-tier Regulatory Acceptable Concentrations (=Tier-1 RACs) based on acute toxicity data for D. magna, A. bahia, Chironomus spp. and G. pulex. These
Tier-1 RACs were obtained by dividing the acute toxicity values by an $\mathrm{AF}$ of 100 (i.e. $\left(48-96 \mathrm{~h} \mathrm{E}(\mathrm{L}) \mathrm{C}_{50}\right) / 100$ ). In addition, the $\mathrm{NOEC} / \mathrm{EC}_{10}$ values of the 28-day water-spiked C. riparius test was used to derive a Tier-1 RAC by dividing it by an $\mathrm{AF}$ of 10 . Note that in the aquatic risk assessment for insecticides these Tier-1 RACs always are compared with the $\mathrm{PEC}_{\max }$. $\mathrm{NOEC}_{\mathrm{eco}}$ values for each insecticide were plotted against the RAC based on:

1. The acute toxicity $\left(\mathrm{EC}_{50}\right)$ for D. magna and an $\mathrm{AF}$ of $100(=\mathrm{Dm} / 100)$;

2. The $\mathrm{NOEC} / \mathrm{EC}_{10}$ of the water spiked 28-day $C$. riparius test and an $\mathrm{AF}$ of $10(=28 \mathrm{dCr} / 10)$;

3. The lowest toxicity value from the acute $\mathrm{EC}_{50} / 100$ for D. magna and the $28 \mathrm{~d}-\mathrm{NOEC} / 10$ for $C$. riparius $(=\mathrm{Dm} /$ 100 and $28 \mathrm{dCr} / 10$ );

4. The acute toxicity for A. bahia and an AF of $100(\mathrm{Ab} / 100)$;

5. The acute toxicity for an OECD-Chironomus sp. (i.e. C. riparius, $C$. dilutus (=Chironomus tentans), C. yoshimitsui (OECD 2011)) and an AF of 100. When data were available for more than one species, the most sensitive was selected $(=\mathrm{Chir} / 100)$;

6. The acute toxicity $\left(\mathrm{EC}_{50}\right)$ for G. pulex and an $\mathrm{AF}$ of 100 $(\mathrm{Gp} / 100)$;

7. The lowest acute toxicity value $\left(\mathrm{EC}_{50}\right)$ from the $D$. magna and A. bahia tests and an AF of $100(=(\mathrm{Dm} \&$ $\mathrm{Ab}) / 100)$;

8. The lowest acute toxicity value $\left(\mathrm{EC}_{50}\right)$ from the $D$. magna and OECD-Chironomus tests and an AF of 100 (=(Dm \& Chir $) / 100)$;

9. The lowest acute toxicity value $\left(\mathrm{EC}_{50}\right)$ from the $D$. magna, A. bahia or OECD Chironomus tests and an $\mathrm{AF}$ of $100(=(\mathrm{Dm} \& \mathrm{Ab} \& \mathrm{Chir}) / 100)$.

These RACs were compared with the 1:1 Tier-1 RAC/ $\mathrm{NOEC}_{\text {eco }}$ ratio. Compounds falling below the 1:1 line indicate that Tier-1 RAC values derived from single-species toxicity tests are protective of ecological effects towards arthropod communities in semi-field studies characterised by a single or repeated pulsed treatment regime.

\section{Results}

Single-species acute toxicity data and $\mathrm{NOEC}_{\mathrm{eco}}$ values could be compared for 31 insecticides which were categorized in one of seven groups (Table 1). The Tier-1 RAC based exclusively on the acute $\mathrm{EC}_{50}$ values for $D$. magna and the application of an AF of 100 was generally protective for organophosphates, carbamates and seven of the eleven pyrethroid cases (Fig. 2a). In contrast, similar RACs were not protective for any of the neonicotinoids evaluated since their Daphnia $\mathrm{EC}_{50} / 100$ values were considerably higher (a factor of 28 to 

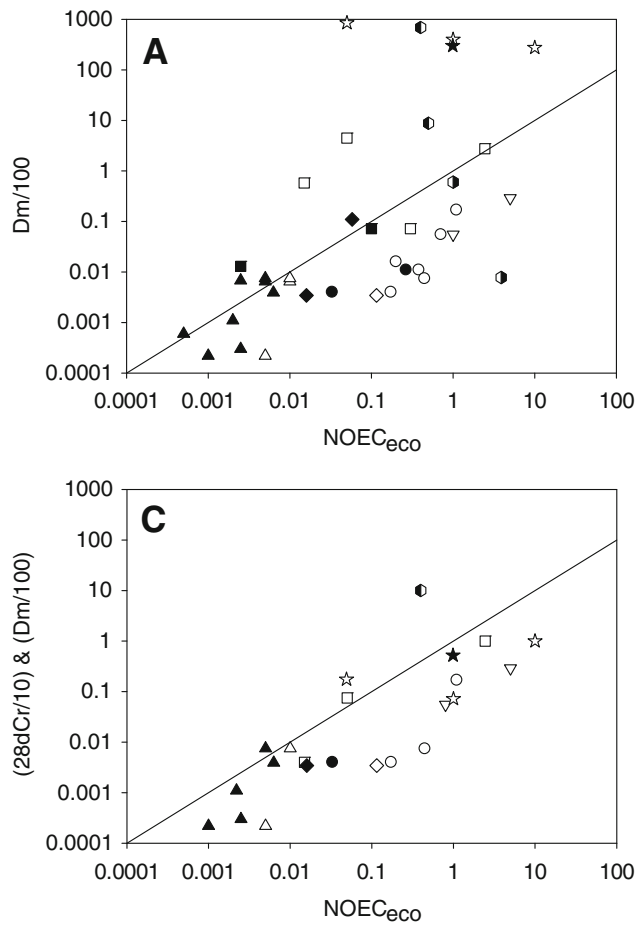

Fig. 2 Plot of the acute Tier-1 RACs for insecticides against NOEC $_{\text {eco }}$ values derived from aquatic micro-/mesocosm tests. The line represents the 1:1 ratio $\left(\mathrm{RAC}_{\mathrm{NOEC}} \mathrm{eco}\right)$. A RACs exclusively based on the acute toxicity data for $D$. magna $(\mathrm{Dm} / 100)$; b RACs exclusively based on $28 \mathrm{~d} \mathrm{NOEC} / \mathrm{EC}_{10}$ for C. riparius $(28 \mathrm{dCr} / 10)$; $\mathbf{c} \mathrm{RACs}$ based on the lowest toxicity value of the combination acute $\mathrm{EC}_{50} / 100$ for $D$. magna

17,020) than the $\mathrm{NOEC}_{\mathrm{eco}}$, irrespective of exposure regime. Also three of the six IGR cases showed a RAC that was more than a factor of 5 to 10 greater that the line representing the $1: 1$ ratio. One biopesticide was a factor of 2 above this line as well as two compounds of the 'other insecticides' category by a factor of 17 to 1,718 (Fig. 2a).

RACs exclusively based on long-term toxicity data (28d NOEC) for C. riparius (water spiked test in the presence of sediment) and the application of an AF of 10 also appeared not to be sufficiently protective for eight of the twenty-three insecticide cases evaluated (Fig. 2b), although the deviations from the 1:1 line were less extreme (a factor of 2 to 25) than observed for the RAC based on acute toxicity of Daphnia. These eight insecticide cases comprised four pyrethroids and one organophosphate, IGR, neonicotinoid and 'other insecticides' each.

When Tier-1 RACs were derived on the basis of the lowest value from the $28 \mathrm{~d} \mathrm{NOEC} / 10$ for $C$. riparius and $48 \mathrm{~h} \mathrm{EC}_{50} / 100$ for D. magna (Fig. 2c) then the protection improved compared with the Tier-1 RACs based on the separate species (Fig. 2a, b). In Fig. 2c the Tier-1 RAC values for four of the 23 insecticide cases were a factor of 2 to 25 higher than their $\mathrm{NOEC}_{\text {eco }}$ values.
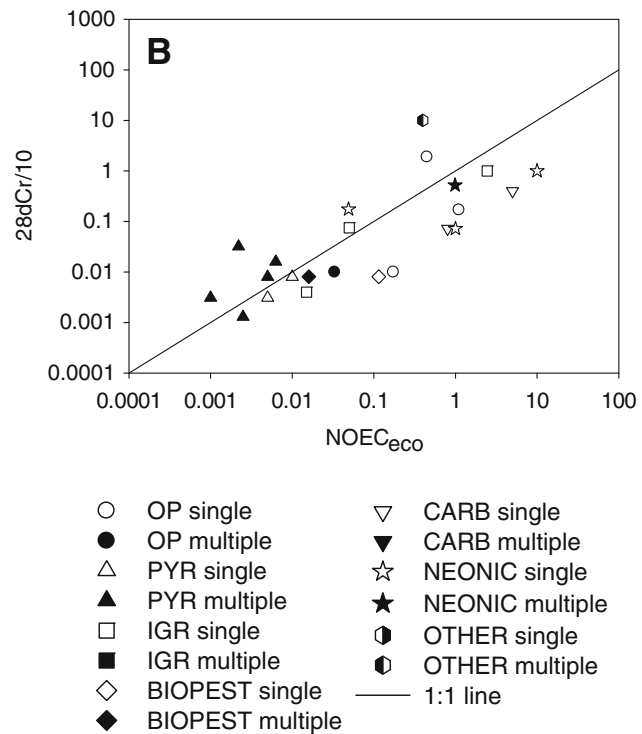

and the $28 \mathrm{~d}-\mathrm{NOEC} / 10$ for $C$. riparius $(\mathrm{Dm} / 100$ and $28 \mathrm{dCr} / 10) . O P$ organophosphates, $P Y R$ pyrethroids, $I G R$ benzylurea/insect growth regulators, NEONIC neonicotinoids, BIOPEST biopesticides, CARB carbamates, OTHER other types of insecticides, single single insecticide application in micro-/mesocosm study, multiple repeated insecticide application in micro-/mesocosm study

Tier-1 RACs exclusively based on the acute toxicity for A. bahia $\left(\mathrm{EC}_{50} / 100\right)$ resulted in three exceedences of the $\mathrm{NOEC}_{\text {eco. }}$. The $A$. bahia $\mathrm{EC}_{50} / 100$ value for an IGR was a factor of 75 higher than the corresponding $\mathrm{NOEC}_{\mathrm{eco}}$ while that was a factor of 6 to 7 for two neonicotinoids (Fig. 3a).

Tier-1 RACs based on acute toxicity measured using the acute OECD Chironomus $\left(\mathrm{EC}_{50} / 100\right)$ test exceeded the $\mathrm{NOEC}_{\text {eco }}$ by a factor 19 to 185 for three IGR cases and a factor of 3 for an organophosphate (Fig. 3b). All nicotenoid cases are below the 1:1 line indicating that for neonicotenoids the acute Chironomus test is the best second Tier-1 test species, but less so for IGRs.

Tier-1 RACs based on the acute toxicity for G. pulex $\left(\mathrm{EC}_{50} / 100\right)$ resulted in exceedences of the $\mathrm{NOEC}_{\text {eco }}$ for two neonicotinoids (by a factor of 2 and 90) one biopesticide (by a factor of 5) and one IGR (by a factor of 350) (Fig. 3c).

Tier-1 RACs (acute $\mathrm{EC}_{50} / 100$ ) based on the most sensitive acute toxicity data for D. magna and A. bahia, showed a similar pattern of $\mathrm{NOEC}_{\text {eco }}$ exceedences (Fig. 4a) than when the effect assessment is based on acute toxicity of A. bahia alone (Fig. 3a), illustrating that in general the acute $\mathrm{EC}_{50}$ value for $A$. bahia is lower than that for D. magna.

Tier-1 RACs (acute $\mathrm{EC}_{50} / 100$ ) based on the most sensitive acute toxicity data for D. magna and an OECD-Chironomus generally appeared to be protective for the 
Fig. 3 Plot of the acute Tier-1 RACs for insecticides against $\mathrm{NOEC}_{\text {eco }}$ values derived from aquatic micro-/mesocosm tests. The line represents the 1:1 ratio $\left(\mathrm{RAC}_{\mathrm{NOEC}} \mathrm{eco}_{\mathrm{O}}\right.$ ). a RACs exclusively based on the acute toxicity for A. bahia (Ab/100); b RACs exclusively based on the acute toxicity for Chironomus (OECD species; Chir/100); c RACs exclusively based on acute toxicity data for G. pulex $(\mathrm{Gp} / 100)$. For explanation of symbols, see Fig. 2
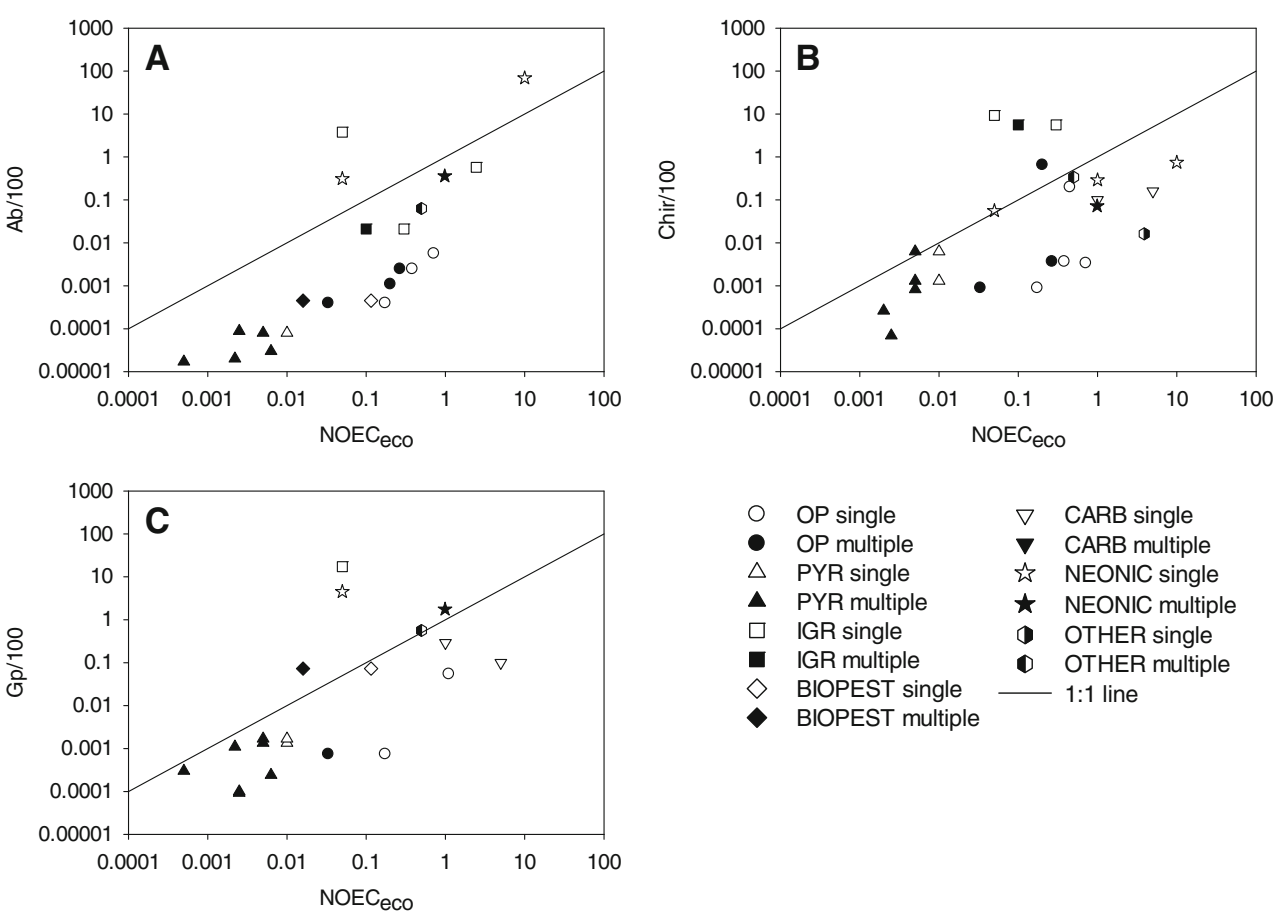

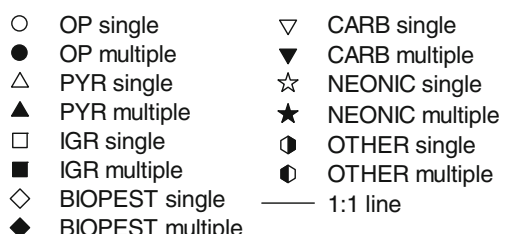

insecticides investigated, except for the IGR fenoxycarb (Fig. 4b).

An overall high level of protection was achieved when deriving Tier-1 RACs (acute $\mathrm{EC}_{50} / 100$ ) based on the most sensitive available acute toxicity value for D. magna, A. bahia and OECD-Chironomus, but again the Tier-1 RAC of one IGR (fenoxycarb) considerably exceeded its NOE$\mathrm{C}_{\text {eco }}$ (Fig. 4c).

\section{Discussion}

Whether the Tier-1 effect assessment procedure on basis of the old data requirements (as presented in Fig. 2) is protective or not seems to depend on the specific toxic mode-ofaction of the insecticide evaluated. In the case of organophosphates, carbamates and pyrethroids most Tier-1 RACs based on acute toxicity data for D. magna, or the combination
Fig. 4 Plot of the acute Tier-1 RACs for insecticides against $\mathrm{NOEC}_{\text {eco }}$ values derived from aquatic micro-/mesocosm tests. The line represents the 1:1 ratio $\left(\mathrm{RAC} / \mathrm{NOEC}_{\mathrm{eco}}\right)$. a RACs based on the lowest acute toxicity value for the combination D. magna and A. bahia ((Dm \& $\mathrm{Ab}) / 100)$; b RACs based on the lowest acute toxicity value for the combination D. magna and Chironomus (OECD species; (Dm \& Chir)/100); c RACs exclusively based on the lowest acute toxicity data for the combination D. magna, A. bahia and/or Chironomus ((Dm \& Ab $\&$ Chir)/100). For explanation of symbols, see Fig. 2
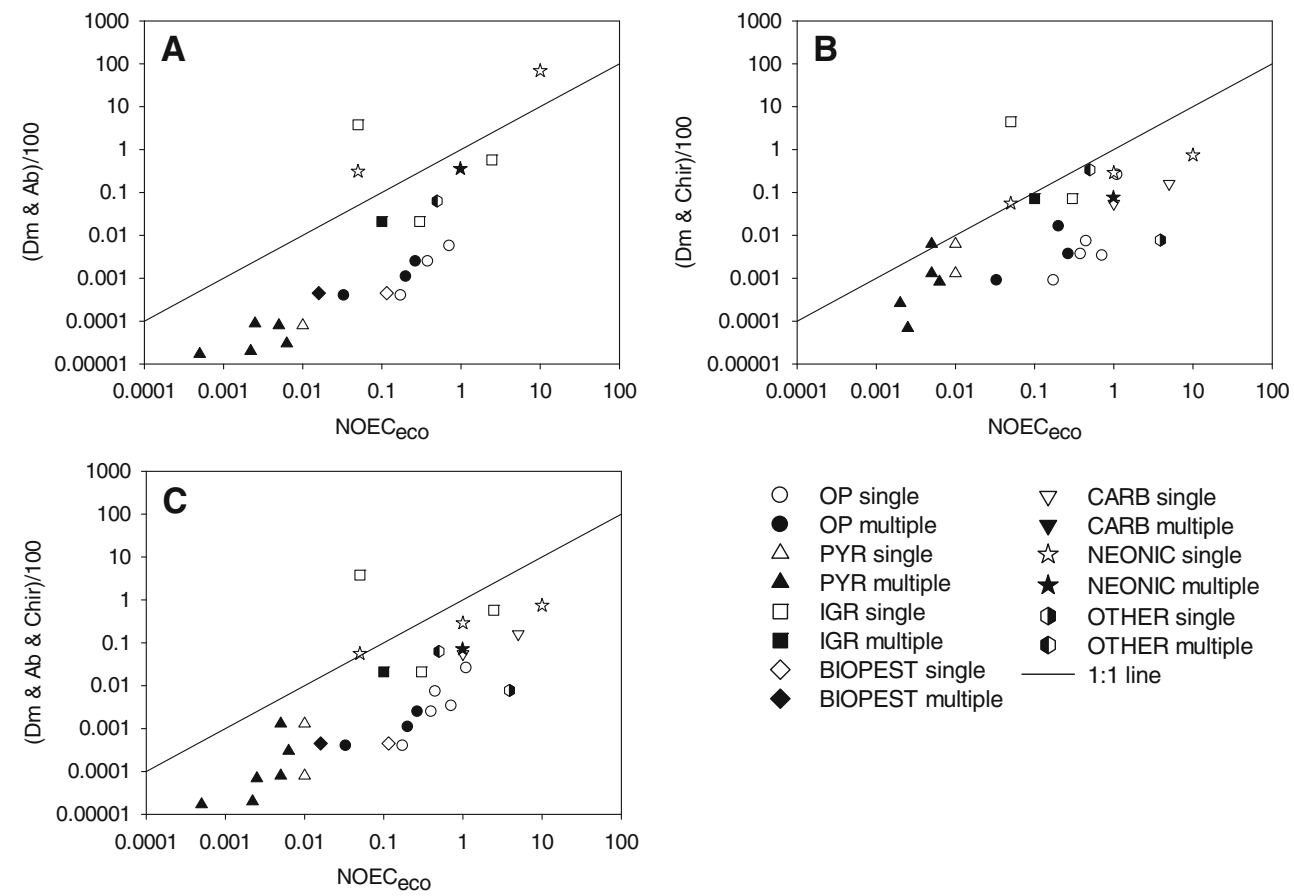
of these data with the $28-\mathrm{d} \mathrm{NOEC} / \mathrm{EC}_{10}$ data for $C$. riparius, are below the $\mathrm{NOEC}_{\mathrm{eco}}$. However, the Tier-1 RACs for some other types of insecticides are above the $\mathrm{NOEC}_{\mathrm{eco}}$, hence, not protective, particularly when these Tier-1 RACs are exclusively based on acute toxicity data for D. magna. Our evaluation clearly demonstrates that for insecticides with very specific modes-of-action, such as neonicotinoids and insect growth regulators, the concentration on basis of the $\mathrm{EC}_{50}$ of Daphnia and the application of an AF of 100 may not always protect sensitive invertebrates in micro-/mesocosm studies. Although by additionally using results of the 28-d water spiked C. riparius test (and application of the AF of 10) the Tier-1acute effect assessment considerably improves for most of the insecticides evaluated, this combination is still not fully protective for 4 out of 23 cases (for which both the 48-h $\mathrm{EC}_{50}$ data of Daphnia and the 28-day NOEC/EC 10 data of Chironomus were available) (Fig. 2c).

The tier-1 effect assessment procedure on basis of the new data requirements (acute $\mathrm{EC}_{50}$ values for D. magna and A. bahia and/or Chironomus) appears to be protective for the vast majority of insecticides evaluated in micro-/mesocosms (Fig. 4). For the combination D. magna and A. bahia in 3 out of 22 cases the tier-1 RAC was not protective (Fig. 4a) while that was 1 out of 26 cases for the combination D. magna and Chironomus (Fig. 3b) and 1 out of 30 cases for the combination D. magna and either A. bahia or Chironomus (Fig. 4c).

The one case for which the Tier-1 RAC based on the proposed new data requirements was clearly not protective for effects observed in micro-/mesocosms concerned the IGR insecticide fenoxycarb. For this compound the Tier-1 RAC exceeded its NOEC $_{\text {eco }}$ by a factor of 76 to 164 (Fig. 4a-c). The position of fenoxycarb in the plots has to do with the exceptionally broad range of Effect Class 2 concentrations $(0.096-3.2 \mu \mathrm{g} / \mathrm{L})$ reported in the cosm study available (in Smit and Vonk 2008). Note that we used the lowest Effect Class 2 value $(0.096 \mu \mathrm{g} / \mathrm{L})$ in our assessment. Moreover, the effects of fenoxicarb treatment observed in the cosms only involved single-event reductions in abundance of the cladoceran Bosmina longirostris. Clear longterm effects were reported at the next higher concentration of $11 \mu \mathrm{g} / \mathrm{L}$ (Smit and Vonk 2008). In addition, an experimental stream study, focussing on two mayfly populations, demonstrated a NOEC of $5 \mu \mathrm{g} / \mathrm{L}$ (Licht et al. 2004). This might suggest that the lowest Effect Class 2 concentration that we used to derive the $\mathrm{NOEC}_{\text {eco }}$ (by dividing this Effect Class 2 concentration by 2) for fenoxicarb was overly conservative.

The crustacean G. pulex is increasingly used as test species to underpin the aquatic effect assessment of pesticides, the advantages being that it is easy to handle in the laboratory and large enough to measure body burdens, and consequently, it is frequently used to study effects of time-variable exposures by means of toxicokinetic-toxicodynamic models (Ashauer et al. 2007, 2011). As for D. magna, Tier-1 RACs based on the acute toxicity of $G$. pulex are generally protective for neurotoxins (organophosphates, carbamates and pyrethroids), however, for more recently developed chemistries (e.g. neonicotinoids and IGRs) G. pulex may not be a representative sensitive species (Fig. 3c), although it is better than Daphnia (Fig. 2a).

Our evaluation demonstrates that the Tier-1, acute aquatic effect assessment on basis of laboratory $\mathrm{EC}_{50}$ values for Daphnia, A. bahia and/or Chironomus (EU commission regulation proposal for new data requirements) overall is protective for ecological effects due to pulsed insecticide exposures in the (semi-)field, in contrast to a Tier-1 effect assessment on basis of Daphnia alone. A lesson learned is that the Tier-1 effect assessment procedure needs to be critically evaluated/calibrated each time new insecticides with a novel toxic mode-of-action are placed on the market, e.g. by requiring not only the mandatory Tier-1 data but also an appropriate micro-/mesocosm study if read-across information is not available.

For neonicotinoids, and to a lesser extend IGRs, the key issue seems to be that crustaceans, and D. magna in particular, may be substantially less sensitive than aquatic insects (see e.g. Beketov and Liess 2008b). It can be argued that, based on the toxic mode-of-action of the active ingredient evaluated, Tier-1 insecticide studies always should include acute toxicity data for the most sensitive taxonomic group, which may be insects (e.g. the 48h water only test with Chironomus). A comparison of the RACs for IGRs based on the 48-h acute Chironomus test (Fig. 3b) and the 28-day water-spiked C. riparius test in the presence of sediment (Fig. 2b), however, reveals that a test duration of $48 \mathrm{~h}$ may be too short to fully express the acute effects of IGRs. Also in mesocosm experiments latency of effects following short-term exposure to IGRs has been demonstrated (e.g. Brock et al. 2009).

A direct consequence of the possible new data requirements is that the Tier-1 effect assessment procedure becomes more conservative for those types of insecticides (e.g. organophosphates, carbamates, pyrethroids) that are already sufficiently covered by the Tier-1 RAC on basis of Daphnia. For example in Fig. 4c, that compares the NOE$\mathrm{C}_{\text {eco }}$ values with the acute Tier-1 RACs on basis of the new data requirements, the organophosphates and pyrethroids are on average a factor of 158 and 59 below the 1:1 line. This again may trigger more expensive higher-tier tests for these compounds. A possible solution to overcome unnecessary higher-tier testing is to calculate the Tier-1 RAC for insecticides by applying an AF of 100 to the geometric mean $\mathrm{EC}_{50}$ value (see EFSA 2005) of the available aquatic arthropod taxa in the core data set, if (1) sufficient readacross information for related compounds is available to 
underpin this approach and, (2) for the insecticide under evaluation the acute $\mathrm{EC}_{50}$ values for D. magna en Chironomus differ less than an order of magnitude. Alternatively, the default approach may be to apply the Geomean approach separately for crustaceans and insects and to select the lowest value. In a future paper we will calibrate the different options for the Geomean approach on basis of acute $\mathrm{EC}_{50}$ values for standard and additional arthropod test species and insecticides by comparing the RACs thus obtained with results of micro-/mesocosm tests.

Acknowledgements The research presented is financially supported by the Dutch Ministry of Economic affairs, Agriculture and Innovation (project BO-12.7-004-001) and the Alterra Vernieuwingsimpuls 2011 (project 5238598). We thank Ivo Roessink for his help in improving Figs. 2, 3 and 4 and two anonymous reviewers for their constructive comments on an earlier version of the manuscript.

Open Access This article is distributed under the terms of the Creative Commons Attribution License which permits any use, distribution, and reproduction in any medium, provided the original author(s) and the source are credited.

\section{References}

Åkerblom N, Arbjörk C, Hedlund M, Goedkoop W (2008) Deltamethrin toxicity to the midge Chironomus riparius Meigen - effects of exposure scenario and sediment quality. Ecotox Environ Saf 70:53-60

Ashauer R, Boxall ABA, Brown CD (2007) Simulating toxicity of carbaryl to Gammarus pulex after sequential pulsed exposure. Environ Sci Technol 41:5528-5534

Ashauer R, Hintermeister A, Potthof E, Escher BI (2011) Acute toxicity of organic chemicals to Gammarus pulex correlates with sensitivity by Daphnia magna across most modes of action. Aquat Toxicol 103:38-45

Beketov MA (2004) Comparitive sensitivity to the insecticides deltamethrin and esfenvalerate of some aquatic insect larvae (Ephemeroptera and Odonata) and Daphnia magna. Russ J Ecol 35:200-204

Beketov MA, Liess M (2008a) Potential of 11 pesticides to initiate downstream drift of stream macroinvertebrates. Arch Environ Contam Toxicol 55:247-253

Beketov MA, Liess M (2008b) Acute and delayed effects of the neonicotinoid insecticide thiacloprid on seven freshwater arthropods. Environ Toxicol Chem 27:461-470

Beketov MA, Schäfer RB, Marwitza A, Paschkec A, Liess M (2008) Long-term stream invertebrate community alterations induced by the insecticide thiacloprid: effect concentrations and recovery dynamics. Sci Total Environ 405:96-108

Boesten JJTI, Köpp H, Adriaanse PI, Brock TCM, Forbes VE (2007) Conceptual model for improving the link between exposure and effects in the aquatic risk assessment of pesticides. Ecotoxicol Environ Saf 66:291-308

Brock TCM, Arts GHP, Maltby L, Van den Brink PJ (2006) Aquatic risks of pesticides, ecological protection goals and common aims in European Union Legislation. Integr Environ Assess Manag 2: e20-e46

Brock TCM, Roessink I, Belgers JDM, Bransen F, Maund SJ (2009) Impact of a benzoyl urea insecticide on aquatic macroinvertebrates in ditch mesocosms with and without non-sprayed sections. Environ Toxicol Chem 28:2191-2205
Campbell PJ, Arnold DJS, Brock TCM, Grandy NJ, Heger W, Heimbach F, Maund SJ, Streloke M (1999) Guidance document on higher-tier aquatic risk assessment for pesticides (HARAP). SETAC-Europe Publication, $179 \mathrm{p}$

Daam MA, Crum SJH, Van den Brink PJ, Nogueira AJA (2008) Fate and effects of the insecticide chlorpyrifos in outdoor plankton dominated microcosms in Thailand. Environ Toxicol Chem 27:2530-2538

De Jong FMW, Brock TCM, Foekema EM, Leeuwangh P (2008) Guidance for summarizing and evaluating aquatic micro- and mesocosm studies. RIVM Report 601506009, Bilthoven, the Netherlands, $59 \mathrm{p}$

De Knecht JA, Van Herwijnen (2008) Environmental risk limits for deltamethrin. RIVM Letter Report 601716015/2008

EC (1991) Council Directive 91/414/EEC of 15 July 1991 concerning the placing of plant protection products on the market. Off J Eur Union 230:1-32

EC (2002) Guidance document on aquatic ecotoxicology in the context of the Directive 91/414/EEC. European Commission, Health \& Consumer Protection Directorate-General, SANCO/3268/2001 rev, 4 (final), Brussels (BE)

EC (2009) Regulation (EC) No 1107/2009 of the European parliament and the council of 21 October 2009 concerning the placing of plant protection products on the market and repealing Council Directives 79/117/EEC and 91/414/EEC. Off J Eur Union 309:1-50

EC (2011) Commission Regulation (EU) No 544/2011 of 10 June 2011 implementing Regulation (EC) No 1107/2009 of the European Parliament and of the Council as regards the data requirements for active substances. Off J Eur Union 155:1-66

EFSA (2005) Opinion of the Scientific Panel on Plant health, Plant protection products and their Residues on a request from the EFSA related to the assessment of the acute and chronic risk to aquatic organisms with regard to the possibility of lowering the assessment factor if additional species were tested. EFSA J $301: 1-45$

EFSA (2010) Scientific opinion on the development of specific protection goal options for environmental risk assessment of pesticides, in particular in relation to the revision of the Guidance Documents on Aquatic and Terrestrial Ecotoxicology (SANCO/ 3268/2001 and SANCO/10329/2002). EFSA J 8(10):1821 (55 pp)

Galic N, Hommen U, Baveco H, Van den Brink PJ (2010) Potential application of population models in the European ecological risk assessment of chemicals II: review of models and their potential to address environmental protection aims. Integr Environ Assess Manag 6:338-360

Giddings JM, Barber I, Warren-Hicks W (2009) Comparitive aquatic toxicity of the pyrethroid insecticide lambda-cyhalothrin and its resolved isomer gamma-cyhalothrin. Ecotoxicology 18:239-249

Guy M, Singh L, Mineau P (2011) Using field data to assess the effects of pesticides on Crustacea in freshwater aquatic ecosystems and verifying the level of protection provided by water quality guidelines. Integr Environ Assess Manag 7:426-436

Langer-Jaesrich M, Köhler HR, Gerhardt A (2011) Assessing toxicity of the insecticide thiacloprid on Chironomus riparius (Insecta: Diptera) using multiple end points. Arch Environ Contam Toxicol 58:963-972

Licht O, Jungmann D, Luwichowski K-U, Nagel R (2004) Long-term effects of fenoxycarb on two mayfly species in artificial indoor streams. Ecotoxicol Environ Saf 58:246-255

López-Mancisidor P, Carbonell G, Fernández C, Tarazona JV (2008) Ecological impact of repeated applications of chlorpyrifos on zooplankton community in mesocosms under Mediterranean conditions. Ecotoxicology 17:811-825

Lozano SJ, O’Halloran SL, Sargent KW, Brazner JC (1992) Effects of esfenvalerate on aquatic organisms in littoral enclosures. Environ Toxicol Chem 11:35-47 
Maltby L, Blake N, Brock TCM, Van den Brink PJ (2005) Insecticide species sensitivity distributions: importance of test species selection and relevance to aquatic ecosystems. Environ Toxicol Chem 24:379-388

Maltby L, Brock TCM, Van den Brink PJ (2009) Fungicide risk assessment for aquatic ecosystems: importance of interspecific variation, toxic mode of action and exposure regime. Environ Sci Technol 43:7556-7563

Maund SJ, Van Wijngaarden RPA, Roessink I, Warinton JS, Van den Brink PJ, Brock TCM (2008) Aquatic fate and effects of lambdacyhalothrin in model ecosystem experiments. In: Gan J, Spurlock F, Hendley P, Weston D (eds) Synthetic pyrethroids: occurrence and behavior in aquatic Environments. Symposium Series No. 991, American Chemical Society, Washington DC, pp 335-354

Moermond CTA (2008). Environmental risk limits for pyriproxyfen. RIVM Letter report 601716022/2008

Nienstedt KM, Brock TCM, Van Wensem J, Montforts M, Hart A, Aagaard A, Alix A, Boesten J, Bopp SK, Brown C, Capri E, Forbes F, Köpp H, Liess M, Luttik R, Maltby L, Sousa JP, Streissl F, Hardy AR (2011) Developing protection goals for environmental risk assessment of pesticides using an ecosystem services approach. Sci Total Environ 415:31-38

OECD (2004) Sediment-water chironomid toxicity test using spiked water, Test Guideline 219, OECD Guidelines for the testing of chemicals. OECD, Paris

OECD (2011) OECD guideline for the testing of chemicals. Chironomus sp., acute immobilisation test. Test guideline 235, OECD guidelines for the testing of chemicals. OECD, Paris

Posthuma-Doodeman CJAM (2008) Environmental risk limits for imidacloprid. RIVM Letter Report 601716018/2008

Roessink I, Arts GHP, Belgers JDM, Bransen F, Maund SJ, Brock TCM (2005) Effects of lambda-cyhalothrin in two ditch microcosm systems of different trophic status. Environ Toxicol Chem 24:1684-1696

Scheepmaker JWA (2008a) Environmental risk limits for teflubenzuron. RIVM Letter report 601716023/2008

Scheepmaker JWA (2008b) Environmental risk limits for abamectin. RIVM Letter report 601716003/2008

Schroer AFM, Belgers D, Brock TCM, Maund SJ, Van den Brink PJ (2004) Acute toxicity of the pyrethroid insecticide lambdacyhalothrin to invertebrates of lentic freshwater ecosystems. Arch Environ Contam Toxicol 46:324-335

Smit CE, Vonk JW (2008) Environmental risk limits for fenoxycarb. RIVM Letter Report 601716008/2008
Solomon KR, Brock TCM, De Zwart D, Dyer SD, Posthuma L, Richards SM, Sanderson H, Sibley PK, Van den Brink PJ (eds) (2008) Extrapolation practice for ecotoxicological effect characterization of chemicals. CRC Press, Boca Raton, $380 \mathrm{pp}$

Stoughton SJ, Liber K, Culp J, Cessna A (2008) Acute and chronic toxicity of imidacloprid to the aquatic invertebrates Chironomus tentans and Hyalella azteca under constant- and pulse-exposure conditions. Arch Environ Contam Toxicol 54:662-673

Streloke M, Köpp H (eds) (1995) Long-term toxicity test with Chironomus riparius: Development and validation of a new test system. Mitteilungen aus der Biologischen Bundesanstalt für Land- und Forstwirtschaft, No 315, BBA, Berlin (DE)

Van den Brink PJ, Van Wijngaarden RPA, Lucassen WGH, Brock TCM, Leeuwangh P (1996) Effects of the insecticide Dursban 4E (a.i. chlorpyrifos) in outdoor experimental ditches. II. Invertebrate community responses. Environ Toxicol Chem 15:1143-1153

Van den Brink PJ, Blake N, Brock TCM, Maltby L (2006) Predictive value of species sensitivity distributions for effects of herbicides in freshwater ecosystems. Hum Ecol Risk Assess 12:645-674

Van Leeuwen LC, Vos JH, Mensink BJWG (2008) Environmental risk limits for lambda-cyhalothrin. RIVM Letter report 601716001/2008

Van Vlaardingen PLA, Vonk JW, De Jong FMW (2008) Environmental risk limits for esfenvalerate. Letter report 601716017/2008

Van Wijngaarden RPA, Brock TCM, Van den Brink PJ (2005a) Threshold levels for effects of insecticides in freshwater ecosystems: a review. Ecotoxicology 14:353-378

Van Wijngaarden RPA, Brock TCM, Douglas MT (2005b) Effects of chlorpyrifos in freshwater model ecosystems: the influence of experimental conditions on ecotoxicological thresholds. Pest Manag Sci 61:923-935

Van Wijngaarden RPA, Brock TCM, Van den Brink PJ, Gylstra G, Maund SJ (2006) Ecological effects of spring and late summer applications of lambda-cyhalothrin in freshwater microcosms. Arch Environ Contam Toxicol 50:220-239

Van Wijngaarden RPA, Barber I, Brock TCM (2009) Effects of the pyrethroid insecticide gamma-cyhalothrin on aquatic invertebrates in laboratory and outdoor microcosm tests. Ecotoxicology 18:211-224

Webber EC, Deutch WG, Bayne DR, Seesock WC (1992) Ecosystemlevel testing of synthetic pyrethroid insecticide in aquatic mesocosms. Environ Toxicol Chem 11:87-105

Weltje L, Rufli H, Heimbach F, Wheeler J, Vervliet-Scheebaum M, Hamer M (2010) The chironomid acute toxicity test: development of a new test system. Integr Environ Assess Manag 6:301-307 